\title{
Educação Fiscal e Eficiência Pública: um Estudo das suas Relações a partir da Gestão de Recursos Municipais
}

\section{Resumo:}

Neste trabalho aborda-se a temática da educação fiscal como variável influente sobre a eficiência pública municipal medida por meio da relação entre despesas com funções de governo e receitas tributárias próprias. São apresentados os fundamentos da educação fiscal a partir dos pressupostos apontados pela Escola de Administração Fazendária e da Teoria da Educação Tributária (Sainz de Bujanda, 1967), associada aos fundamentos de natureza pedagógica, preconizados por Saviani $(1980 ; 2008)$ e Chaves (2007). No aspecto metodológico, o trabalho propôs a mensuração do nível de educação fiscal dos cidadãos, por intermédio da instrumentalização de um questionário eletrônico, aplicado a uma amostra de 1.804 respondentes. Os dados municipais foram obtidos da base Finanças Brasil - Finbra, coletados diretamente do sítio da Secretaria do Tesouro Nacional, e compreendem informações relativas aos exercícios de 2004 a 2010, sendo a amostra final definida para análise da eficiência de 689 municípios. Os dados inicialmente foram tratados por Análise Envoltória de Dados (DEA) e análise fatorial com o objetivo de definir as variáveis que permitissem a aplicação da análise regressão múltipla. Pelos resultados, rejeita-se a hipótese principal da pesquisa de que o nível de educação fiscal do cidadão se reveste em um instrumento de controle social que influencia a eficiência da gestão de recursos públicos e aumenta o nível de transparência e accountability da administração pública municipal. Recomendase a realização de estudos em uma perspectiva confirmatória dos achados, envolvendo outras variáveis não abordadas no estudo, como indicadores sociais, bem como utilizando outros grupos de indivíduos não alcançados pela pesquisa.

Palavras-chave: Educação Fiscal. Eficiência Pública. Gestão de Recursos.

\section{Erivan Ferreira Borges}

Doutor pela Universidade de Brasilia (UnB) e Professor Adjunto II da Universidade Federal do Rio Grande do Norte (UFRN). Contato: Campus Universitário, CCSA - Departamento de Ciências Contábeis, Lagoa Nova, Natal, RN. CEP.: 59078-970. E-mail: erivanfborges@gmail.com

\section{José Matias Pereira}

Doutor em Ciência Política pela Universidade Complutense de Madri, Espanha e Professor e pesquisador associado da Universidade de Brasilia (UnB). Contato: Campus da UnB, Prédio FACE, Asa Norte, Brasília, DF. CEP.: 70000-910.

E-mail: matias@unb.br 


\section{Introdução}

A construção da cidadania exige que a sociedade conheça de forma adequada as instituições e a atuação do Estado e, em particular, da sua atividade financeira, visto que esta diz respeito, de forma direta, aos seus interesses, como contribuinte. Para que isso ocorra, é essencial que o cidadão seja estimulado a participar de forma efetiva na elaboração, na implementação e na avaliação de políticas públicas e programas de governo. Essa participação - que vai além do simples pagamento de tributos - tem início com o processo de elaboração do orçamento - com destaque para as receitas, as despesas e o crédito público. Assim, ao lado de outras instituições da sociedade civil, o Estado deve estimular e facilitar o acesso do cidadão a essas informações (Matias-Pereira, 2009b).

Como pode o Estado promover o estímulo e facilitar esse acesso? Essa é uma questão que para a Escola de Administração Fazendária (Esaf) pode ser respondida a partir das ações de governo voltadas à formação fiscal do cidadão. Para a entidade, enquanto gestora do Programa Nacional de Educação Fiscal (PNEF) (Escola de Administração Fazendária [ESAF], 2004), a educação fiscal apresenta-se como um programa necessário, pois uma das esferas mais negligenciadas pela sociedade é a do conhecimento, significado econômico, financeiro e social do tributo, principal fonte da receita pública. Recentemente, essa temática vem sendo difundida nos três níveis do governo, caracterizados por programas que objetivam promover a conscientização do cidadão, e permitir que este reflita sobre o seu real papel na ligação com o Estado (Esaf/MF/MEC, 2009).

Ao representar o marco em nível nacional para as demais iniciativas, o PNEF caracteriza o estudo da educação fiscal como um elemento de relevância, aplicando-se à sociedade, aos diversos ramos empresariais e ao próprio Estado, principal interessado em transmitir e difundir o que representa a administração fiscal dos tributos e como estes influenciam as diversas políticas e programas por ele implementadas.

A educação fiscal contribui para a formação da consciência do cidadão, orientando-o para princípios que norteiam a construção de um sistema tributário que visa à distribuição de renda mais igualitariamente (Escola de Administração Fazendária [ESAF], 2004). Borges, Nascimento, Costa e Costa (2008) delimitam que o conhecimento dos fundamentos que identificam a educação fiscal pode proporcionar ao governo redimensionar suas políticas de inserção social.

Silveira e Silveira (2006) entendem que muitas atividades e muitos projetos governamentais vêm sendo implementados com o propósito de adequar os instrumentos de controle ao novo modelo de gestão pública proporcionado pela Constituição da República Federativa do Brasil de 1988 (2001), especialmente os ligados à transparência, ao controle social e ao exercício da cidadania. Para os autores, porém, o que tem sido realizado ainda não está formalizado em sistemas, programas, projetos, atividades e ações de accountability.

Por essas considerações, parte-se do pressuposto, a partir do que entende a Esaf, de que a educação fiscal representa um instrumento relevante para elevar o nível de compreensão e de participação do cidadão no processo de elaboração e implementação das políticas públicas e programas de governo no país. Dessa forma, pode colaborar para elevar, também, a transparência e os resultados das políticas e programas direcionados ao bem comum da população, em especial, a promoção da inclusão social e, assim, alcançar uma maior eficiência das atividades e ações governamentais.

Entendidas como um processo latente na discussão do que vem a ser estado de bem-estar social, essas inquietações são abordadas no meio acadêmico, em forma crítica, sob perspectivas de análises e avaliações qualitativas e quantitativas, nas áreas de Educação, Sociologia, Economia, Administração e Gestão Pública, e nas Ciências Contábeis (Musgrave \& Musgrave, 1980; Meny \& Thoenig, 1992; Stiglitz, 1999; Freire, 2005; Calmon \& Costa, 2009; Matias-Pereira, 2009a; Slomski, 2008) são exemplos de estudiosos que abordam essas temáticas.

Na perspectiva contábil, Reis, Slomski, Pereira e Mello (2007) consideram que o processo de participação social na administração tributária também é consequente da falta de ação discricionária do Estado, que provoca no cidadão que paga o tributo uma necessidade de obter informações claras sobre a aplicação desses recursos por parte de quem arrecada. Como sistema de informação de caráter 
social, a contabilidade pode colaborar com a disseminação dessas informações, mensurando, registrando, divulgando e fornecendo dados que podem ser utilizados, por exemplo, para a medição da eficiência pública, contexto de utilidade presentes em alguns trabalhos recentemente realizados no Brasil, tais como os de Campelo (2003), Resende, Slomski e Corrar (2005), Scarpin (2006), Jubran (2006), Faria, Januzzi e Silva (2008), Jubran e Jubran (2010) e Rocha, Macedo e Corrar (2010).

Esses estudos buscam medir a eficiência de programas, políticas e da gestão pública de recursos nos três níveis de governo, mas não esgotam, por suas análises e modelos, a pesquisa sobre o tema. Considerando as investigações que fazem uso de indicadores contábeis, esses trabalhos, de certa forma, evidenciam um volume de pesquisas dentro da Contabilidade Pública direcionadas ao contexto gerencial, como reflexo do entendimento de que a preocupação com a coisa pública não deve ser apenas com aplicação dos recursos de forma correta, sob o aspecto legal, mas também sob a ótica da eficácia e da eficiência na aplicação (Reis et al., 2007).

Essas considerações possibilitam inferir que a utilidade da informação contábil pode facilitar o processo decisório e, por conseguinte, interferir, por sua interpretação, no desempenho das organizações. Essa característica informativa da contabilidade faz dela o meio necessário ao gerenciamento das transações efetuadas pelo governo, principalmente na administração e no gerenciamento dos tributos. Ela é responsável por um volume significativo de transações dentro de um país, mas a grande maioria das discussões na Ciência Contábil tem focado o setor privado, sendo residual a pesquisa no setor público (Niyama \& Silva, 2008, p. 278)

Reis et al. (2007) ponderam sobre essa lacuna e concluem seu trabalho afirmando que, apesar do avanço das pesquisas na Contabilidade Pública, ela ainda é incipiente sob diversos aspectos e, basicamente, tem se concentrado na investigação das áreas gerencial, na geração de informações para usuários externos sobre a Lei de Responsabilidade Fiscal, Orçamento Público e Balanço Social.

Pela importância atribuída à Contabilidade por alguns dos principais dispositivos legais que regulam as contas públicas no Brasil (Lei n. ${ }^{\circ} 4.320$ (1964), e Lei Complementar 101 (2000), que é a Lei de Responsabilidade Fiscal), parece razoável considerá-la como uma ferramenta, um instrumento de controle social capaz de facilitar a relação Estado-Cidadão.

Resumidamente, parece que a busca pela eficiência pública envolve um aspecto educativo voltado à conscientização cidadã a respeito do significado socioeconômico do tributo, cujo entendimento passa, obrigatoriamente, pelo conhecimento do sistema de informações (contabilidade) que gerencia os recursos que o Estado arrecada e deve aplicar em favor da sociedade. Mas será que o atual processo educativo brasileiro engloba essa conscientização e, da forma em que está, permite controle social sobre as ações públicas? Essas ponderações promovem certa inquietação acadêmica e são tomadas como elementos motivadores à realização deste trabalho, destacando-se que:

a) não se observam, na literatura, discussões empíricas envolvendo o contexto da educação fiscal como instrumento de controle social capaz de influenciar a gestão de recursos públicos;

b) a busca pela eficiência pública presume a investigação de quais seriam as variáveis influentes ao seu alcance, o que de certa forma abre espaço para a pesquisa acadêmica, envolvendo a influência da educação fiscal e dos programas de governo nesse sentido, como é o caso do PNEF;

c) a Contabilidade se reveste do caráter de principal sistema de informações tradutor das contas públicas para a sociedade, mas sua aplicação nesse setor tem sido considerada incipiente por muitos autores.

Essas considerações conduzem à efetivação do presente estudo, que tem como tema central a influência da educação fiscal sobre eficiência pública na gestão de recursos, utilizando as informações geradas pela Contabilidade Pública municipal como elemento suporte à investigação. Nessa perspectiva, define-se como problema central de pesquisa a seguinte questão: A educação fiscal do cidadão influencia a eficiência da gestão de recursos pela administração pública municipal? 


\section{Fundamentação Teórica}

Pode-se considerar que a discussão que leva em conta a educação fiscal da sociedade está associada à teoria das Finanças Públicas, à teoria dos Tributos e à teoria da Educação Tributária, fundamentos subjacentes utilizado no debate da temática, e consolidados na literatura econômica e jurídica a partir de trabalhos, como os de Musgrave e Musgrave (1980), Stiglitz (1999) e Sainz de Bujanda (1967), e no Brasil, presentes nos trabalhos de Matias-Pereira (2009a).

Esse enquadramento no campo das finanças públicas, presume-se, dá uma identidade à discussão da temática, que, ao longo do tempo, pelo menos no contexto nacional, vem sendo discutida como uma área de conhecimento específico, sem vinculação a quais seriam suas bases.

\subsection{Educação Fiscal e a Teoria da Educação Tributária}

O processo educativo permeia todas as áreas do conhecimento e, em uma escala evolutiva, provoca o desenvolvimento de valores e atitudes nos cidadãos, que, no contexto político, integram os fundamentos da cidadania e do sentimento democrático. Isso significa que o processo de conscientização social, inclusive tributário, não é fruto do acaso, mas resultado de um conjunto de ações coordenadas resultantes do processo educativo por que passa o homem (Sainz de Bujanda, 1967; Lobo, Paramio, Garcia-Verdugo, Muñio \& Garcia, 2005; Freire, 2005).

Sainz de Bujanda (1967) afirma que a educação tributária deve ser objeto de um ramo importante da ciência pedagógica, pressuposto que leva o teórico espanhol a propor a Teoria da La Eduction Tributária, em cujos fundamentos o trabalho também se apoia.

Para ele, a educação fiscal é resultado de uma formação sistêmica voltada à conscientização do contribuinte sobre o papel social do tributo. Na sua formulação, o autor considera que a educação fiscal está e deve estar inserida no contexto geral da educação, dentro da ciência da Pedagogia, uma vez que deve se preocupar com os problemas da sociedade e suas possíveis soluções.

Sustenta ainda que a educação fiscal não deve se restringir a uma disciplina, pois sua efetividade é resultado de um processo global que envolve todo o conhecimento que permeie a formação da personalidade do indivíduo. Qualquer tipo de abordagem sobre o tema que não se apoie em uma consideração geral da personalidade do contribuinte será unilateral e insuficiente (Sainz de Bujanda, 1967).

Para ele, entre as operações lógicas que conduzem o conceito de educação fiscal, estão o entendimento dessa educação dentro do contexto educativo geral e da análise científica dos elementos que conduzem o comportamento do contribuinte.

Além de apresentar o conceito, o autor faz um levantamento quanto aos ideais da educação fiscal, seus métodos de abordagem e os resultados que esse processo traz em termos sociais. Os ideais se fundamentam na determinação de conteúdos educativos concretos e no repertório de ações que integram o comportamento do contribuinte educado, a fim de que este cumpra suas obrigações e deveres e, ao mesmo tempo, fiscalize a ação estatal no âmbito tributário. Para alcançar esses ideais, o autor ressalta que é importante fortalecer o sentido ou o sentimento de responsabilidade moral, dentro de uma abordagem psicológica sobre a importância do tributo para a sociedade, mas sem se deixar levar pelo perigo do psicologismo fiscal.

Para isso, salienta a importância do educador no seu papel de disseminar as boas práticas de administração financeira. Ao mesmo tempo, deve eliminar presunções culturais que prejudicam o comportamento ético em relação ao tributo por parte do cidadão, tais como o entendimento equivocado do Fisco e, por conseguinte, sobre todo o Estado, como um usurpador do que é coletivo.

O teórico também considera importante que, para o alcance desses objetivos, sejam implantadas políticas de informação tributária. Por suas colocações, considera que a educação tributária pode ajudar a consolidar a justiça e a racionalidade do sistema tributário, e a simplificar a administração financeira do Estado, dando um novo sentido ao processo tributário. 
Como resultados desse processo de conscientização, que pode ser dito psicológico e moral, o autor aponta o alcance da justiça e da racionalidade do sistema tributário e consequente simplificação da administração financeira nos países. Esses pontos acabam por moldar, dar um novo sentido ao processo tributário, tudo em função da elevação do nível educativo da coletividade.

Ao se analisar os fundamentos apontados pelo teórico, observa-se que existe uma presunção de influência do conhecimento sobre o significado socioeconômico do tributo por parte da sociedade sobre a gestão pública dos recursos que arrecada. Essa mesma presunção está presente nos fundamentos do Programa Nacional de Educação Fiscal, apesar de os documentos que integram o pacote educativo elaborado pela Gerência Nacional de Educação Fiscal (Geref) não fazer referência a teoria apontada.

\subsubsection{Sobre o Estado da Arte da Pesquisa em Educação Fiscal}

A pesquisa $e$ as experiências internacionais relacionadas à discussão da educação fiscal têm recebido grande atenção dos pesquisadores latinos, a maioria ligada ao Instituto de Estudos Fiscais Espanhol (Fernández \& Ruiz, 2002; Lobo et al., 2005; Lobo \& Garcia, 2008; Garcia, 2008; Yubero, Lobo, Verdugo, Paramio, Garcia, Anel, Conesca, Ramos \& Zuazu, 2009). As análises, com prevalência dos aspectos institucionais e teóricos, concentram-se nas bases do programa de educação fiscal da união europeia e o do programa de educação cívico tributário da Espanha.

No trabalho de Lobo et al. (2005), intitulado La Educacion Fiscal en España, os autores fazem uma discussão aprofundada das experiências educativas da administração tributária espanhola, que se concentram em repassar aos jovens e adolescentes as noções básicas do sistema fiscal daquele país.

A discussão traça um mapa das experiências dos programas de educação fiscal adotadas na Europa, a América do Norte, a América Latina e o Pacífico, especificamente de países como a Finlândia, França, Itália, Suíça, do Reino Unido (que inclui a Escócia, País de Gales e Irlanda do norte), Ucrânia, Dinamarca, Suécia e Noruega, Canadá, Estados Unidos, México, Argentina, Bolívia, Colômbia, Costa Rica, Chile, México, Panamá, Peru, República Dominicana, Venezuela, Brasil, Austrália, Japão, e Nova Zelândia.

As experiências, em geral, têm em comum a preocupação com a cidadania e a consciência cívicofiscal e evidenciam como as políticas e os programas voltados à educação fiscal são gerenciados pelo governo de cada país.

Essas preocupações estão presentes em outros estudos (como Diaz \& Garcia, 1999, Cisne \& Menezes, 2001, Yubero, Lobo \& Garcia, 2008, Yubero et al., 2009, Estévez e Esper, 2009, Instituto de Estudios Fiscales, Area de Sociología Tributaria, 2008; Giarrizzo e Sivori, 2010; García e Escobar, 2011) que tratam desse e de outros assuntos transversais ao tema, mas com focos diferentes ao objetivo deste trabalho.

O que se percebe na análise desses estudos é a preocupação em estabelecer diretrizes conjuntas de atuação entre os sistemas educacionais e tributários de cada país através dos órgãos de governo responsáveis pelas áreas, tendo como pressuposto imediato que a conscientização e a consequente atuação cidadã, em termos tributários, começam a partir da educação global do indivíduo e devem estar presentes na sua vida desde a formação básica.

No Brasil, o volume da produção acadêmica sobre o tema ainda pode ser considerado incipiente, conforme apontam Grzybovski e Hahn (2006). Não se verifica, nos trabalhos existentes, investigações em uma perspectiva pedagógica, dentro da filosofia da educação, como avaliação de programa de governo, ou em uma perspectiva de mensuração, como variável capaz de influenciar a eficiência pública.

Existe uma vasta literatura sobre os temas transversais que fundamentam o PNEF (controle social, accountability, justiça fiscal, cidadania), mas nada que qualifique essa associação de conceitos como um corpo coordenado que represente a base subjacente de uma efetiva educação fiscal. Destacam-se os trabalhos de Pertuzatti e Merlo (2005), Pereira (2005), Sholz (2005), Grzybovski e Hahn (2006), Lima (2008), Neves (2008) e Borges et al. (2008), que trazem perspectivas diferentes quanto à abordagem do tema, sem considerar os objetivos traçados para essa pesquisa. 
No contexto contábil, destaca-se o trabalho de Pertuzatti e Merlo (2005), que representa o primeiro ensaio acadêmico publicado em um periódico científico brasileiro que trata do tema educação fiscal, associando a temática ao contexto contábil. Até então, os textos eram caracterizados pela publicação pulverizada de pequenas análises, críticas e apresentações nos eventos promovidos pela ESAF e pelas secretarias estaduais responsáveis. Essas iniciativas, associadas às desenvolvidas por entidades como o Banco Interamericano de Desenvolvimento (BID), deram início a um trabalho de disseminação dos fundamentos da educação fiscal, como uma prática possível e necessária.

\subsection{Eficiência Pública}

Pode-se considerar que a busca pela relação ótima entre os bens e serviços consumidos e os bens e serviços produzidos tem sido o objetivo recorrente de governos que adaptaram suas estratégias as relações introduzidas pela nova administração pública. Conceitualmente traduzido como eficiência, este objetivo não é destaque apenas nas investigações acadêmicas, mas presentes nos modelos de governos, como aqueles desenvolvidos no Reino Unido e Estados Unidos, cujas práticas tornaram-se exemplos e referências para a atuação de outras nações (Peña, 2008, Freitas Jr. \& Pereira, 2009).

Não é objetivo do trabalho discorrer sobre os caminhos que levaram a administração pública (com o modelo gerencial) a romper com os modelos anteriores a sua existência (patrimonialista e burocrático), mas se considera importante frisar, com base nas afirmações de Freitas Jr. e Pereira (2009, p.2), que a maneira gerencial como os governos tratam seus programas e projetos desenvolve-se a partir da estrutura criada pelo modelo burocrático, e com ele coexiste. Para os autores, Gerencialismo e Burocracia, cada um com as suas armas, buscam acabar com as manifestações do Patrimonialismo, como o nepotismo e o personalismo da administração pública.

Correlacionando os diferentes modelos de administração pública, esses autores ilustram a dinâmica dessas relações, incluindo o modelo Societal, que se embasa em uma participação efetiva do cidadão.
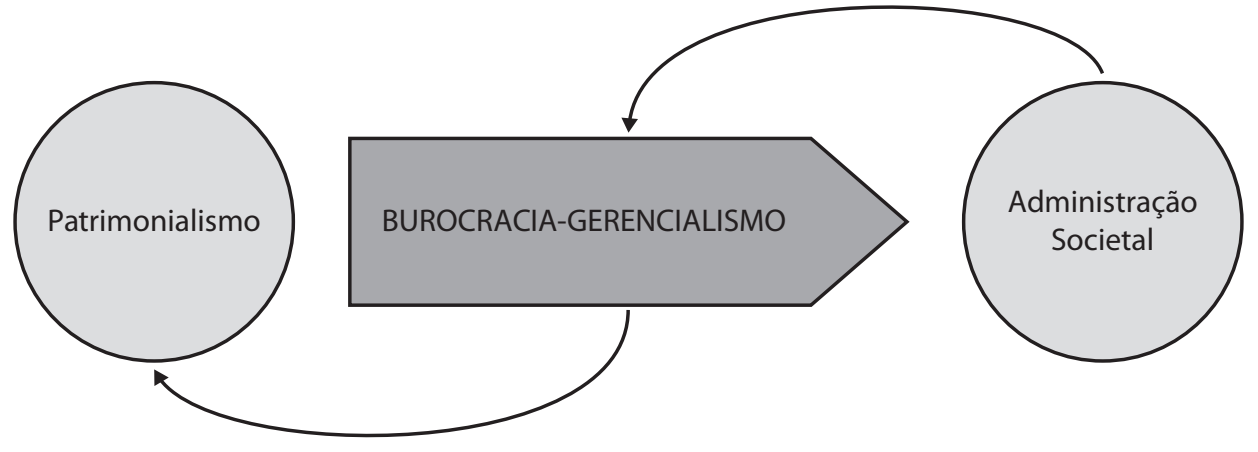

Figura 1. Dinâmica entre os Modelos de Administração Pública Fonte: Freitas Jr. e Pereira (2.009, p. 2)

A análise dessa dinâmica, construída a partir de uma visão evolutiva da maneira de administrar o que é público, do confundir-se governo com governante, à participação efetiva do cidadão no processo de gestão, tem como característica a busca pela eficiência, seja ela técnica ou econômica.

Em um contexto de observação eminentemente monetário, as ações dos governos devem ter como premissa básica a minimização de gastos e consequente obtenção do melhor serviço a ser prestado ao cidadão. Conforme já referenciado, essas condições são agrupadas no conceito de eficiência, também traduzida como a adequação entre a valoração do resultado e o custo empregado para a sua realização (Marques, 2004).

Para Baracho (2006, p. 141), o grau de eficiência é dado pela relação existente entre os bens e serviços consumidos e os bens ou serviços produzidos; ou pelos serviços prestados (outputs) em relação aos recursos empregados (inputs). 
Objeto de vários estudos, com interpretações, conotações e enfoques diferentes, o conceito de eficiência geralmente é associado aos termos eficácia, efetividade, economicidade, legalidade e legitimidade (Baracho, 2006, Campelo, 2003; Peña, 2008). Tais conceitos, apesar de representarem medidas de equilíbrio e avaliação das ações nos processos de gestão pública e estarem inerentemente ligados à eficiência, não são foco deste trabalho, que analisa a eficiência a partir do pressuposto contábil entre os recursos aplicados e arrecadados.

Apesar da multiplicidade de enfoques, alguns autores (Musgrave \& Musgrave, 1980; Stiglitz, 1999, Matias-Pereira, 2009c) entendem que o Ótimo de Pareto representa o melhor e mais restrito conceito para o termo eficiência:

[...] dado um certo arranjo econômico, esse é eficiente se não puder existir um rearranjo que deixe alguém em melhor situação sem piorar a posição dos outros. Nessa situação, é impossível uma alteração do método de produção, ou do conjunto de bens produzidos, ou do tamanho de setor público, que ajude A sem prejudicar B e C. (Matias-Pereira 2009c, p. 60).

Analisando o conceito, Matias-Pereira (2009c, p. 60) argumenta que a eficiência está relacionada ao método com o qual são realizadas as ações pretendidas, o que possibilita considerar, dentro dos limites estabelecidos para o trabalho, que a maneira pela qual o processo de conscientização sobre o significado econômico do tributo é repassado ao cidadão pode interferir diretamente na sua atuação como controlador social. Nesse sentido, se sua atuação for impregnada dos fundamentos apontados pelo PNEF, pode influenciar positivamente os indicadores econômicos, financeiros e orçamentários dos municípios.

\section{Metodologia}

O plano operacional do trabalho está dividido em tipo de pesquisa, população e amostra, instrumentos de pesquisa e variáveis de estudo, coleta, análise e tratamento de dados, e análise dos resultados.

\subsection{Tipo de Pesquisa}

A pesquisa é caracterizada como exploratório-descritiva, sendo realizada em duas etapas distintas. A primeira etapa, de caráter exploratório, objetivou proporcionar ao pesquisador um maior envolvimento com o problema, e o consequente aprimoramento de ideias e descobertas sobre o assunto, resultando em uma melhor sistematização para a segunda etapa (descritiva), conforme aponta Gil (2006, p. 43). Esse autor considera que muitas vezes as pesquisas exploratórias constituem a primeira etapa de uma investigação maior quando o tema escolhido é bastante genérico, o que exige seu esclarecimento e delimitação por meio da revisão da literatura ou discussão com especialistas, por exemplo. $O$ resultado desse processo é a obtenção de um problema mais esclarecido, passível de investigação mediante procedimentos mais sistematizados pelo pesquisador.

A segunda etapa tem um caráter descritivo (em uma perspectiva confirmatória) e objetiva validar as dimensões da educação fiscal suportadas na fase inicial, cujos resultados possibilitem ao pesquisador estabelecer as relações entre as hipóteses de pesquisa construídas para o trabalho.

\subsection{População e Amostra}

A população e a amostra quanto à mensuração do nível de educação fiscal dos cidadãos são determinadas a partir do conjunto de respostas ao instrumento de pesquisa, enviado pelo critério de acessibilidade a base de e-mails do pesquisador e da sua rede de contatos. 
O instrumento considerou as bases do PNEF, programa que foi desenvolvido para promover e institucionalizar a educação fiscal para o pleno exercício da cidadania, uma vez que para seus articuladores "[...] é um trabalho de sensibilização da sociedade para a função socioeconômica do tributo". Além disso, a Esaf contribui enviando o instrumento à sua base de dados.

Quanto às informações de natureza financeira e contábil, a população-alvo é composta pelos 5.564 (cinco mil quinhentos e sessenta e quatro) municípios brasileiros. A amostra, parcialmente determinada a priori, compreende o total de municípios nos quais o PNEF tenha sido formalmente implantado ou esteja em processo de sensibilização, além daqueles municípios, não implantados ou sensibilizados, que concentrem um número de respostas significantes para mensuração da educação fiscal da população local.

O Plano Estratégico da Esaf 2008/2011 define que o conceito de implantação refere-se à formalização do programa por meio de lei ou decreto municipal devidamente editado, ou pela instituição de um grupo de trabalho.

A justificativa para a delimitação da amostra é permitir o pressuposto de comparabilidade, necessário no processo de avaliação e evolução da gestão, características essenciais que devem permitir o alcance da resposta ao problema central da pesquisa.

No tratamento dos dados são considerados apenas como integrantes efetivos da amostra aqueles municípios que tenham prestado à STN todas as informações contábeis em cada ano, sendo excluídos aqueles que não informaram, ou o fizeram com omissões.

O conjunto de dados é composto pelos montantes das receitas próprias e despesas por funções de governo per capita, entre os períodos de 2004 e 2010, definidas como variáveis operacionais para aplicação da DEA.

\subsection{Estimação e Definição dos Modelos}

Como referenciado, o estudo foi realizado em duas etapas distintas, com o objetivo de obter as variáveis que suportariam utilização da análise de regressão múltipla.

A regressão múltipla é uma técnica estatística que desenvolve, simultaneamente, uma relação matemática entre duas ou mais variáveis independentes e uma variável dependente escalonada por intervalo. Proporciona o entendimento sobre como uma ou mais variáveis influenciam outras (Stock \& Watson, 2004; Hair, Anderson, Tatham \& Black, 2005; Wooldridge, 2006, Cunha \& Coelho, 2011).

Segundo a fundamentação teórica de Hair et al. (2005, p. 13), a técnica é o exemplo mais amplamente difundido e conhecido de uma variável estatística entre as técnicas multivariadas. Para sua efetivação, o desenho metodológico adotado, aderente às considerações propostas por Hair et al. (2005), exigiu a construção de dois indicadores testáveis, cuja relação estatística prevista assume que a variável dependente (eficiência) pode ser explicada pelo indicador (e suas dimensões) de educação fiscal.

O resultado dos tratamentos de dados relacionados às duas variáveis principais são objetos de outros dois estudos dos mesmos autores, nos quais são feitos detalhamentos da aplicação das técnicas e metodologias utilizadas para definir a eficiência dos municípios (Análise Envoltória de Dados) e o nível de educação fiscal dos cidadãos (análise fatorial).

Os resultados e os procedimentos adotados quanto à definição das variáveis foram sintetizados, estando assim traduzidas:

Variável dependente - Nível de eficiência dos municípios (EfPub) - Obtida pela aplicação de um modelo DEA com Retornos Variáveis (RVE), output orientado. Para estimação dos modelos, optou-se por utilizar um modelo baseado em folgas, o SBM (Slacks-basedmeasure) A estimação da fronteira evidenciou um total de 689 municípios com escores de eficiência testáveis. 
Variáveis Independentes - Nível de educação fiscal por município $(E d F)$ - Obtidos pela aplicação de análise fatorial sobre as respostas ao instrumento, com quatro dimensões latentes evidenciadas. As respostas obtidas, uma vez ordenadas por origem de cidade/estado, evidenciaram um total de 475 municípios com níveis de educação da sua população.

Variável Dummys - Determinadas características dos municípios componentes da amostra não são prontamente observáveis, exigindo o estabelecimento de variáveis de controle sobre os modelos estimados. O método mais adequado para efetuar esse controle é a utilização de variáveis binárias (dummy's). Sua utilização pressupõe que, dada certa condição aos componentes de uma amostra, se um componente a satisfizer, essas variáveis assumem o valor 1, caso contrário, assumem 0 . Para este trabalho, as seguintes variáveis foram categorizadas como dummy's:

1. População do Município (Npop): Município com população até 50 (cinquenta) mil habitantes assumem o valor de 0 (zero); acima desse contingente, 1(um);

2. Implantação de programas de educação fiscal (IProgEDF): Municípios com programas implantados assumem o valor de zero (zero), não implantados, 1 (um).

Para definir o modelo final, inicialmente foram testados dois conjuntos de informações por meio da metodologia dos Mínimos Quadrados Ordinários (MQO), considerando (a) como variável dependente do escore de Eficiência do Município no ano 2010; e, em seguida, (b) o escore médio de eficiência do município nos anos de 2004 a 2010. Como variáveis independentes, foram utilizadas as dimensões validadas na análise fatorial, IComp, ISocEcon, IjustEti, IComCor, além das dummy's IProgEDF, Npop.

A conclusão quanto ao modelo mais adequado surgiu após a realização de 16 (dezesseis) estimações com diferentes modelos alternativos e métodos distintos, tais como o GMM, TOBIT, Logístico, GLM e Dados Censurados, com e sem restrições. Essas estimações consideraram os modelos com e sem o intercepto (constante) na equação.

Os modelos GMM e TOBIT resultaram em performances muito próximas daquelas que o método MQO apresentou, optando-se por manter os resultados decorrentes desse método por ser mais parcimonioso. As Tabelas 1 a 3 apresentam o resumo do modelo com melhor adequação aos objetivos da pesquisa.

\section{Tabela 1}

\section{Resumo do Modelo Estimado}

\begin{tabular}{cccccc} 
Modelo & $\mathbf{R}$ & $\mathbf{R 2}$ & $\mathbf{R} 2$ Ajustado & Erro Padrão da estimativa & Durbin-Watson \\
\hline 2 & $0,800 c$ & 0,640 & 0,638 & 0,25134 & 2,157 \\
\hline
\end{tabular}

Fonte: dados da pesquisa

Tabela 2

Anova

\begin{tabular}{|c|c|c|c|c|c|c|}
\hline & & Soma dos Quadrados & DF & Média dos Quadrados & $\mathbf{F}$ & Sig. \\
\hline \multirow{3}{*}{2} & Regressão & 53,091 & 2 & 26,545 & 420,225 &, $000 c$ \\
\hline & Resíduos & 29,879 & 473 &, 063 & & \\
\hline & Total & $82,970 b$ & 475 & & & \\
\hline
\end{tabular}

Fonte: dados da pesquisa 
Tabela 3

Coeficientes das variáveis

\begin{tabular}{|c|c|c|c|c|c|c|c|c|c|c|}
\hline & \multirow[t]{2}{*}{ Modelo } & \multicolumn{2}{|c|}{$\begin{array}{l}\text { Coeficientes } \\
\text { Não- } \\
\text { padronizados }\end{array}$} & \multirow{2}{*}{$\begin{array}{c}\text { Coeficientes } \\
\text { Padronizados } \\
\text { Beta }\end{array}$} & \multirow[t]{2}{*}{$T$} & \multirow[t]{2}{*}{ Sig. } & \multicolumn{2}{|c|}{$\begin{array}{c}\text { Intervalo de } \\
\text { Confiança de } 95,0 \% \\
\text { para B }\end{array}$} & \multicolumn{2}{|c|}{$\begin{array}{l}\text { Estatística de } \\
\text { Colinearidade }\end{array}$} \\
\hline & & B & $\begin{array}{c}\text { Erro } \\
\text { Padrão }\end{array}$ & & & & $\begin{array}{l}\text { Limite } \\
\text { Inferior }\end{array}$ & $\begin{array}{l}\text { Limite } \\
\text { Superior }\end{array}$ & Tolerância & VIF \\
\hline \multirow{2}{*}{2} & LNCorrup & 0,026 & 0,002 & 0,524 & 13,731 & 0,0000 * & 0,023 & 0,03 & 0,523 & 1,911 \\
\hline & Npop & 0,209 & 0,023 & 0,343 & 8,989 & 0,0000 ** & 0,163 & 0,255 & 0,523 & 1,911 \\
\hline
\end{tabular}

Fonte: dados da pesquisa

Pelos escores observados, o valor de $\mathrm{R}^{2}$ Ajustado do modelo indica que as variáveis independentes incluídas na equação explicam $63,8 \%$ das variações sobre a eficiência pública. A variável $N P O P$ é responsável por $57,7 \%$ dessa explicação, percentual mais expressivo que os $6,1 \%$ explicados pela variável LN-IComCor. O erro padrão de 0,25134 demonstra o melhor ajustamento da regressão em comparação aos modelos que foram desconsiderados, e os seus resíduos indicam que o modelo é mais preciso, com melhor nível de significância. Esse fato evidencia que pelo menos uma das variáveis independentes exerce efetiva influência sobre a eficiência municipal medida por meio da DEA. A equação do modelo estimado está representada abaixo:

$$
\text { EfPub }_{i}=0,026 x \text { LNCorrup }_{i}+0,209 \times \text { Npop }_{i}+\varepsilon_{i}
$$

Para a aplicação da análise de regressão, alguns autores (Stock \& Watson, 2004, Hair et al., 2005, Cunha \& Coelho, 2011) afirmam que é importante seguir alguns critérios de desenvolvimento e obedecer alguns pressupostos básicos, aplicando-se testes quanto à linearidade dos coeficientes e das variáveis, a normalidade e a homocedasticidade dos resíduos e a ausência de autocorrelação. Isso garante o adequado ajustamento, a integridade e a significância do modelo. Os diagnósticos realizados pressupõem que o modelo, consoante aos testes, às estimações e às correções realizadas, atende aos objetivos da pesquisa, sendo considerado robusto para fins de análise.

\section{Análise de Resultados}

Algumas considerações são feitas em relação aos resultados, procurando-se entender cada fenômeno observado, mas se tendo o cuidado, diante dos pressupostos necessários à validação do modelo, de não prever comportamentos ou direcionamentos das unidades avaliadas em função da influência da educação fiscal sobre o modelo.

A primeira análise envolve a validação das três primeiras hipóteses delineadas para a pesquisa, sob o pressuposto de confirmar, ou não, a educação fiscal como algo mensurável, com múltiplas dimensões. As duas metodologias aplicadas confirmam que existem elementos que caracterizam e identificam a formação e educação fiscal do indivíduo, permitindo mensurá-la em mais de uma dimensão.

A primeira metodologia utilizada para fundamentar essa constatação, indicou que os cidadãos compreendem o seu papel e o papel do Estado nessa busca, corroborando os fundamentos assumidos pela Esaf para disseminar a educação fiscal como um instrumento necessário ao crescimento da sociedade. Essa constatação, porém, é feita apenas sob a premissa teórica do entendimento, não se refletindo diretamente sobre a eficiência pública municipal.

Um dos pressupostos básicos da educação fiscal é o entendimento de sua existência como parte de um processo educacional maior. Um processo que envolva não apenas a formação profissional, estruturada no rol de disciplinas que tratem de conhecimentos específicos, tais como os relativos à geografia, física 
ou história, mas associados a outros que capacitem os indivíduos a participarem ativamente das ações do Estado, visto que este representa o consciente coletivo sobre justiça e equidade, e pode mediar a convivência social (Sainz de Bujanda, 1967; ESAF, 2004).

Como parte do contexto geral da educação, esperava-se que os fundamentos da educação fiscal, traduzidos pelos indicadores propostos, fossem capazes de evidenciar influência significativa sobre a eficiência pública, uma vez que alguns trabalhos que fundamentam a pesquisa consideram que iniciativas educacionais influenciam fortemente a eficiência das entidades públicas.

Os dois fatores mais influentes sobre o processo são o aspecto populacional do município e o entendimento coletivo sobre a necessidade de combater a corrupção. A priori, o primeiro aspecto reforça as constatações sobre a precariedade reinante nos pequenos municípios brasileiros, que, na sua maioria, dependem exclusivamente de repasses e transferências para sobreviverem financeiramente. Essa condição acaba por inibir investimentos mais robustos em educação e, por consequência, em programas e projetos voltados à consciência fiscal. Como educar para a consciência fiscal quando não é possível a mínima consciência civil? Essa é uma questão que não deve ser refutada diante dos resultados observados.

Isso, presume-se, acaba por afastar, com algumas exceções, qualquer pressão social sobre os governantes dessas cidades, tornando-as ineficientes em comparação com municípios maiores.

Por outro lado, essa constatação não parece ser resultado apenas do aspecto financeiro que prevalece nesses pequenos municípios, mas também da forma adotada para tentar disseminar a prática da educação fiscal. Isso presume uma reavaliação desse processo, considerando não apenas o processo educacional formal, mas a forma como vem sendo oferecida, notadamente direcionada ao funcionalismo público e a um grupo de cidadãos que tem acesso a ferramentas que, muitas vezes, estão longe de serem alcançadas pela maioria dos residentes nos pequenos municípios brasileiros, tais como recursos de informática e acesso à internet.

Não se furta aqui a importância do programa ou das bases que o sustentam, mas o seu direcionamento. Conforme foi verificado, apesar do alto grau educacional dos respondentes (86,80\% com curso superior, sendo que 55,5\% destes têm pós-graduação em níveis de especialização, mestrado ou doutorado), a presumível influência da educação fiscal e suas dimensões se restringiu ao aspecto relacionado ao combate à corrupção, talvez pela latente exposição atual na mídia de atos e fatos, relacionando o tema a gestores e entidades públicas. Parece uma resposta tempestiva da sociedade aos acontecimentos.

Dados fornecidos pela Esaf, em junho de 2011, apontavam que o PNEF e seus fundamentos já haviam alcançado mais 70 mil disseminadores locais e mais de 33 mil escolas, com projetos de formalização e implantação de programas em mais de 140 municípios, sem contar com os mais de 400 em processo de sensibilização. Ao se analisarem esses números em relação aos achados e considerando apenas o nível educacional dos respondentes e o total de indivíduos que tiveram treinamento específico sobre o PNEF (49,3\% disseram ter realizado o curso a distância oferecido pela Esaf), fica evidente a necessidade de se rever todo o contexto de abordagem dessa prática pedagógica, que, em tese, não está sendo refletida na prática: o cidadão conhece os fundamentos, entende sua importância, mas isso não influencia as ações públicas para tornar o município mais eficiente.

Por outro lado, é importante destacar alguns pontos sobre a variável de entendimento sobre o combate à corrupção como o maior influente sobre a eficiência.

A literatura sobre gestão pública reforça que, apesar dos princípios maiores que regem o sentimento coletivo sobre o papel do Estado e o conjunto de reformas tomadas para melhorar sua performance, este muitas vezes não alcança eficiência e/ou efetividade, pela existência, por exemplo, do fenômeno da corrupção, e da falta de ética dos operadores públicos (Resende, 2002).

Para o autor, reformas administrativas são políticas públicas, cujo objetivo último é a elevação da performance de um dado sistema burocrático. O não alcance dos objetivos, ou mesmo a busca por melhorias nos resultados, acabam por levar os governos a formularem novas políticas e programas voltados a criar as condições necessárias para a elevação da performance (Resende, 2002). No caso Brasileiro, considera que essas tentativas têm sido historicamente fracassadas, resultando em um contexto de falhas sequenciais. 
Na trajetória acumulada de reformas administrativas (em nível nacional ou subnacional), é nítido o fenômeno recorrente de que as reformas tendem a falhar sequencialmente, e os problemas de performance persistem. As reformas dificilmente conseguem atingir os seus objetivos e novas reformas são formuladas e implementadas para lidar com "antigos problemas" e, nesse sentido, pode-se dizer que elas falham sequencialmente.

O caso brasileiro historicamente representa um modelo de falha sequencial, i.e., as reformas dificilmente conseguiram alterar a performance do aparato burocrático. Baixa performance e elevados gastos têm sido razões para novas reformas, porém, os "crônicos problemas" persistem: clientelismo, corrupção, reduzida eficiência, reduzido grau de profissionalismo, elevados gastos e déficits no setor público, bem como outros males burocráticos (Resende, 2002, p.1).

Esses argumentos parecem justificar os resultados da pesquisa, caracterizando o contexto de abordagem da educação fiscal como uma tentativa de solucionar problemas que podem ser ditos conjunturais dentro da história brasileira. A própria instituição das ações voltadas à disseminação da educação fiscal é historicamente marcada pela descontinuidade, como altos e baixos na sua institucionalização, que data de fevereiro de 1945 com as primeiras iniciativas advindas dos cursos de aperfeiçoamento para os servidores do Ministério da Fazenda, instituído pelo Decreto-Lei n. ${ }^{\circ} 7.311$ (1945), até dezembro de 2003, quando foi editada a Portaria Interministerial n. 413 (2002) dos Ministérios da Fazenda e da Educação, onde foi definida a estrutura geral para a implementação do PNEF.

Ao que tudo indica, sua continuidade depende, conforme analisado, de mais uma revisão, ou reformulação, mas sem o característico de falha sequencial apontado por Resende (2002), de objetivar a melhoria, e acabar por fomentar antigos problemas.

Como a busca por resultados é uma fixação do novo paradigma público e, segundo o governo, isso significa atender às demandas, aos interesses e às expectativas dos beneficiários, sejam cidadãos ou organizações, criando valor público (Secretaria de Gestão do Ministério do Planejamento, 2009, p. 6), parece que a primeira iniciativa a ser tomada, diante dos achados da pesquisa, é extirpar o problema da corrupção.

\section{Conclusões}

A tentativa de medir a influência da educação fiscal sobre eficiência pública na gestão de recursos, utilizando as informações geradas pela contabilidade como elemento suporte evidenciou que não há reflexo direto significante, em termos multidimensionais, dessa educação sobre a eficiência investigada. Portanto, dentro dos limites do trabalho, não se pode afirmar que o nível de educação fiscal dos cidadãos influencia positivamente a eficiência da gestão, medida por meio de indicadores econômicos, financeiros e orçamentários dos municípios brasileiros.

De forma particular, observou-se que, além do contingente populacional, variável mais influente no modelo, a dimensão relacionada ao combate à corrupção exerce alguma influência sobre a eficiência testada, mas em níveis bem menos representativos. Presume-se que o contexto da pesquisa e a latente exposição na mídia de atos e fatos relacionando o tema a gestores e entidades públicas provocou a inclusão dessa dimensão no modelo, como uma resposta social imediata aos acontecimentos.

Do ponto de vista da gestão pública, os resultados evidenciam a necessidade de se investigarem e estabelecerem, no contexto do Programa Nacional de Educação Fiscal, ações práticas de alcance social que atendam às demandas, interesses e expectativas dos beneficiários dessas ações, materializando o paradigma público pela busca de resultados, sob pena de, mais uma vez, se confirmarem as falhas sequenciais apontados por Resende (2002).

São muitas as questões que se levantam a partir dos resultados observados, principalmente diante das limitações inerentes à pesquisa, apesar do seu rigor metodológico. Destacam-se aqui as principais limitações, compreendendo: 
- O instrumento de mensuração: as dimensões previstas para definição do instrumento levam em consideração conceitos e princípios entendidos pela gestora do PNEF como as bases principais para propor um nível de conhecimento sobre educação fiscal. É fato, porém, que o programa deve ter um alcance sistêmico, ou seja, deve alcançar todos os níveis e classes sociais que integram a sociedade, tais como ricos, pobres, alfabetizados, não alfabetizados, entre outros, que podem influenciar, por suas diferentes características, o seu sentimento em relação à função social dos tributos e aos deveres coletivos (do Estado e do cidadão). Portanto, podem existir outras dimensões não diretamente observáveis pela metodologia que foi adotada.

- O comprometimento do pesquisado: os resultados dependem, exclusivamente, do comprometimento individual de cada respondente com a pesquisa, podendo não representar sua verdadeira opinião, principalmente, porque trata de questões de natureza ética, na qual determinados comportamentos antiéticos, quando analisados sob a ótica do "jeitinho" (Barbosa, 2006), podem ser considerados positivos e necessários à sobrevivência.

- A base de Dados: muitos gestores podem não consolidar e informar adequadamente os dados de natureza contábil, financeira e orçamentária na STN, situação que pode determinar outro viés às informações que são utilizadas para o cálculo dos indicadores utilizados.

- A generalização dos resultados em DEA: os resultados observados são específicos para o estudo, ou seja, os critérios de eficiência adotados não podem ser generalizados como os meios mais adequados para outras análises, pois são determinísticos em relação ao estudo.

Por outro lado, é importante frisar que os achados passam a compor o conjunto de motivadores de pesquisa, pois presume: (a) uma contribuição à fomentação e à disseminação da temática da educação fiscal no contexto acadêmico em nível de graduação e pós-graduação associado à Contabilidade e aos seus operadores; (b) confirma a possibilidade de mensuração dessa educação fiscal em forma de indicador; (c) comprova que determinadas características que compõem essa educação podem influenciar a eficiência, independentemente da adoção, ou não, do PNEF e suas bases (pela sensibilização); (d) em uma leitura crítica, confirma e expõe a descontinuidade continuada das políticas e programas de governo brasileiros voltados a desempenho; e, por fim, (e) abre campo científico para revalidação dos achados em uma perspectiva confirmatória, tanto da mensuração da educação fiscal e da eficiência pública como das relações entre esses dois indicadores, pela proposta metodológica utilizada, ou por tratamentos alternativos que se apliquem à tipologia da presente pesquisa.

Por último, recomendam-se novos trabalhos, que, entre outros aspectos relacionados ao tema, investiguem: a) o PNEF e suas bases, a partir de uma avaliação pedagógica do programa, com diretrizes didáticas específicas para grupos de usuários com diferentes níveis educacionais e classes sociais; b) a mensuração dos eventuais impactos de outras variáveis estruturais sobre o PNEF, tais como os níveis de competência da unidade gestora e suas prioridades em relação ao programa e às demais atividades que coordena e gerencia; c) a replicação da presente pesquisa de forma segregada, por região, classes e níveis educacionais, objetivando averiguar se o contexto observado pode ser generalizado; d) o relacionamento da educação fiscal e a eficiência pública medida por meio de indicadores sociais não utilizados no presente trabalho; e) se a efetividade de campanhas sobre educação fiscal ao longo do tempo é resultado da disseminação da pedagógica dos fundamentos, ou do poder discricionário das autoridades que coordenam as campanhas; e, f) o direcionamento dos objetivos desta pesquisa exclusivamente aos beneficiários de programas sociais, ou analfabetos, inclusive funcionais, em uma perspectiva confirmatória. 


\section{Referências}

Baracho, M. A. P. (2006). A importância da gestão de contas públicas municipais sob as premissas da governance e accountability. Rio de Janeiro: Elsevier.

Barbosa, L. (2006). O Jeitinho Brasileiro: A arte de ser mais igual do que os outros. Rio de Janeiro: Elsevier.

Borges, E. F., Nascimento, V. C., Costa, F. M. de S. \& Costa, G. M. (2008). Uma visão exploratória da educação fiscal presente na formação do graduando em ciências contábeis da Universidade Federal do Rio Grande do Norte. Revista Brasileira de Contabilidade, 1(174), pp. 69-83.

Calmon, P. C. D. P. \& Costa, M. M. (2009). Análise de Políticas Públicas no Brasil: estudos sobre a formação da agenda governamental. Anais do ENANPAD, 33, São Paulo, SP, Brasil.

Campelo, C. A. G. B. (2003). Eficiência Municipal: Um estudo no estado de São Paulo. Tese de doutorado. Programa de Pós-Graduação em Administração, Departamento de Administração, Faculdade de Economia, Administração e Contabilidade da Universidade de São Paulo. São Paulo, SP, Brasil.

Constituição da República Federativa do Brasil de 1988. (2001). [Coleção Saraiva de Legislação].

Chaves, A. J. F. (2007). Bases Teóricas da Educação. Universidade Estadual Paulista. Recuperado em 26 março, 2011, de http://www.franca.unesp.br/oep/Eixo\%201\%20-\%20Tema\%203.pdf>.

Cunha, J. V. A. \& Coelho, A. C. (2011). Regressão Linear Múltipla. In: L. J. Corrar, E. Paulo \& J. M. Dias Filho. Análise multivariada para os cursos de administração, ciências contábeis e economia. (1 $1^{\mathrm{a}} \mathrm{ed}$.) São Paulo: Atlas, pp. 131-231.

Decreto-Lei no 7.311, de 8 de Fevereiro de 1945 (1945). Cria, no Ministério da Fazenda, os Cursos de Aperfeiçoamento, e dá outras providências. Diário Oficial da República Federativa do Brasil. Brasília, DF: Poder Executivo.

Escola de Administração Fazendária [ESAF] (2004). Programa Nacional de Educação Fiscal: Educação fiscal no contexto social (Série Educação Fiscal. Cadernos). Brasília, Recuperado em 30 maio, 2012 de http://www.esaf.fazenda.gov.br/parcerias/educacao-fiscal/caderno/caderno_1.pdf .

Estévez, A. M; Esper, S. C. (2009). Ciudadanía fiscal y nuevas formas de relación entre contribuyentes y administración tributaria. Administración Federal de Impuestos. Revista de Ciencias Económicas y Estadisticas-Saberes. 1, pp. 63-74. Sección Artículos. Recuperado em 19 julho, 2011, de http://www. fcecon.unr.edu.ar/revista/index.php/revista/article/view/5/37.

Faria, F. P; Jannuzzi, P.M.; Silva, S. J. (2008). Eficiência dos gastos municipais em saúde e educação: uma investigação através da análise envoltória no estado do Rio de Janeiro. RAP - Revista de Administração Pública. 42(1), pp. 155 -177.

Fernández, J. M. \& Ruiz, M. A. G. (2002), Un paso más en la colaboración tributaria a través de la formación: el programa Fiscalis de la Unión Europea. Instituto de Estudos Fiscales. Doc. 27/02. Madrid. Espanha.

Freire, P. (2005). Pedagogia do oprimido. (44a ed.) Rio de Janeiro: Paz e Terra.

Freitas Jr, D. B. \& Pereira, J. R. (2009). Administração Pública Gerencial em Municípios Mineiros: Uma Avaliação por Meio de Indicadores. Anais ENANPAD, 33, São Paulo, SP, Brasil.

Garcia, M. L. V. (2008). Los impuestos, instrumentos de solidaridad El Programa de Educación Cívico-Tributaria de la Agencia Tributaria española. Instituto de Estudos Fiscales. Madrid, Espanha.

García, G. A. \& Escobar, L. de P. (2011) La conciencia fiscal y el fraude fiscal. Factores que influyenen La tolerancia ante el fraude. Universidad Complutense de Madrid. Recuperado em 19 setembro, 2011 de http://eprints.ucm.es/6859/1/0702.pdf. 
Giarrizzo, V. \& Sivori, J. S. (2010). La inconsistencia de la moral tributaria. El caso de los moralistas evasores. Revista de la Facultad de Ciencias Económicas y Empresariales, Universidad de León . Num. 10 Pecvnia, 10. pp. 95-124.

Gil, A. C. (2006). Métodos e técnicas de pesquisa social. $5^{\mathrm{a}}$ ed. São Paulo: Atlas.

Grzybovski, D. e Hahn, T. (2006). Educação fiscal: premissa para melhor percepção da questão tributária. Revista de Administração Pública (RAP). Rio de Janeiro 40(5): pp. 841-864.

Hair, J. F.; Anderson, R.E.; Tatham, R.L. \& Black, W.C. (2005). Multivariate data analysis. 5a. New Jersey: Prentice Hall.

Instituto de Estudios Fiscales (2008). Área de Sociología Tributaria: Opiniones y actitudes fiscales de los españoles. Documentos del Instituto de Estudios Fiscales, Madrid.

Jubran, A. J. (2006). Modelo de Análise de eficiência na administração pública: Um estudo aplicado as prefeituras brasileiras usando a Análise Envoltória de Dados. Tese de doutorado (Doutorado em Engenharia) Escola Politécnica da Universidade de São Paulo. São Paulo, SP, Brasil.

Jubran, A. J. \& Jubran, L. M. P. (2010). Simulação e análise da eficiência na gestão municipal suportadas por data envelopment analysis. $4^{\circ}$ Congresso Luso brasileiro para o planejamento urbano regional, integrado, sustentável - PLURIS 2010. Universidade do Algarve, em Faro, PORTUGAL.

Lei Complementar 101, de 04 de maio de 2000 (2000). Estabelece normas de finanças públicas voltadas para a responsabilidade na gestão fiscal e dá outras providências. Diário Oficial da República Federativa do Brasil. Brasília, DF: Poder Executivo.

Lei n. 4.320, de 17 de março de 1964 (1964). Estatui Normas Gerais de Direito Financeiro para elaboração e controle dos orçamentos e balanços da União, dos Estados, dos Municípios e do Distrito Federal. Diário Oficial da República Federativa do Brasil. Brasília, DF: Poder Executivo.

Lima, A. S. S. (2008). Uma contribuição ao marketing social e a educação fiscal no Brasil: Análise por meio de casos múltiplos. Rio de Janeiro. Tese. Departamento de Dirección de Empresas y Sociología. Universidad de Extremadura. Badajoz. Espanha.

Lobo, M. L. D.; Paramio, M. F.; Garcia-Verdugo; A. M., Muñio; C.R. \& Garcia, M.L.V. (2005). La Educaion Fiscal en España. Instituto de Estudos Fiscales. Doc. 29/05. Madrid. Espanha.

Matias-Pereira, J. (2009a) Finanças Públicas: A política orçamentária no Brasil. (5ª ed.) São Paulo: Atlas.

Matias-Pereira, J. (2009b) Manual de Gestão Pública Contemporânea. (3ª ed.) São Paulo: Atlas.

Matias-Pereira, J. (2009c). Curso de Administração Pública. (3ª ed.) São Paulo: Atlas.

Marques, M. C. C. (2004). O setor público administrativo e a gestão pública. Revista Brasileira de Contabilidade, 138, pp. 89-138.

Meny, I \& Thoenig, J.C. (1992). Las políticas públicas. Madrid: Ariel.

Musgrave, R. A. \& Musgrave, P. B. (1980). Finanças Públicas: Teoria e Prática. São Paulo: Campus.

Neves, E. P. (2008). Educação Fiscal e Responsabilidade Social: Um estudo de caso na Delegacia da Receita Federal em Feira de Santana. Bahia. Dissertação (Mestrado Profissional Multidisciplinar em Desenvolvimento Humano e Responsabilidade Social) - Centro de Pós-Graduação e Pesquisa Visconde de Cairu. Faculdade Visconde de Cairu.

Niyama, J. K. \& Silva, C. A. T. (2008). Teoria da Contabilidade. São Paulo: Atlas.

Peña, C. R. (2008). Um Modelo de Avaliaçăo da Eficiência da Administração Pública através do Método Análise Envoltória de Dados (DEA). Revista de Administração Contemporânea, Curitiba, 12(1), pp. 83-106. 
Pereira, A. A. (2005). Programa de Educação Tributária da Bahia: A Visão dos atores envolvidos no seu grupo e a implementação do programa. Bahia. Dissertação (Mestrado em Administração) - Núcleo de Pós-Graduação em Administração. Escola de Administração da Universidade Federal da Bahia. Salvador,BA, Brasil.

Pertuzatti, E. \& Merlo, R. A. (2005). O programa de educação fiscal do Estado de Santa Catarina: Uma reflexão sobre o papel do contador. Revista Universo contábil. 1(3), pp. 48-62.

Portaria Interministerial no 413 de 31 de dezembro de 2002 (2002). Define competências dos órgãos responsáveis pela implementação do Programa Nacional de Educação Fiscal - PNEF. Diário Oficial da República Federativa do Brasil. Brasília, DF: Poder Executivo.

Reis, L. G.; Slomski, V.; Pereira, C. A. \& Mello, G. R. (2007). A pesquisa brasileira em contabilidade do setor público. Revista de Informação Contábil (RIC/UFPE). 1(1), pp. 89-101.

Resende, A.; Slomski V. \& Corrar, L. J. (2005). A gestão pública municipal e a eficiência dos gastos públicos: Uma investigação empírica entre as políticas públicas e o índice de desenvolvimento humano (IDH) dos municípios do Estado de São Paulo. Revista Universo Contábil - Blumenau, 1(1), pp. 24-40.

Resende, F. C. (2002). O dilema do controle e a falha sequencial nas reformas gerenciais. Revista do Serviço Público. 53(3), pp. 50-74.

Rocha, A. V. M. A.; Macedo, M. A. S. \& Corrar, L. J. (2010). Avaliação do desempenho das unidades de negócio da SABESP à Luz do seu Balanced Scorecard: um estudo apoiado em DEA. Anais do XIII Simpósio de Administração da Produção, Logística e Operações Internacionais SIMPOI, São Paulo, SP, Brasil.

Sainz Bujanda, F. (1967). Teoría de la educación tributaria. Hacienda y Derecho. Instituto de Estudios Políticos. 9(24), pp. 343-500.

Saviani, D. A Filosofia da Educação e o problema da inovação em educação. In: GARCIA, Walter E. (Coord.). Inovação educacional no Brasil. Problemas e perspectivas. São Paulo: Cortez, 1980. p. 15-29.

Saviani, D.. Pedagogia Histórico-Crítica: primeiras aproximações. 10ª ed. rev. Campinas. São Paulo: Editores Associados, 2008 (coleção educação contemporânea).

Scarpin, J. E. (2006). Estudo dos Fatores Condicionantes do Índice de Desenvolvimento Humano nos municípios do Estado do Paraná: instrumento de controladoria para a tomada de decisões na gestão governamental. São Paulo. Tese de doutorado em Controladoria e Contabilidade do Programa de Pós-Graduação em Ciências Contábeis, Departamento de Ciências Contábeis, Faculdade de Economia, Administração e Contabilidade da Universidade de São Paulo. São Paulo, SP. Brasil.

Secretaria de Gestão do Ministério do Planejamento. Programa Nacional de Gestão Pública e Desburocratização [GESPÚBLICA] (2009). Produto 4: Guia Referencial para Medição de Desempenho na Administração Pública. Brasília, dezembro de 2009. Recuperado em 27 dezembro, 2010, de http:// www.gespublica.gov.br/ferramentas/pasta.2010-05-24.1806203210.

Secretaria do Tesouro Nacional [STN]. Finanças Brasil. Recuperado em 17 maio, 2011, de http://www3. tesouro.fazenda.gov.br/estados_municipios.

Sholz, R. T. (2005). O Princípio da informação no Direito Tributário. Dissertação (Mestrado em Direto) Centro de Ciências Jurídicas e Sociais. Pontifícia Universidade Católica do Paraná - PUC. Curitiba, PR, Brasil, p. 192.

Silveira, J. S. T. \& Silveira, L. D. B. (2006). Desenvolvimento metodológico e aplicação de um índice de accountability aos municípios catarinenses. Anais ENANPAD, 30, Salvador, BA, Brasil.

Slomski, V. (2008). Manual de contabilidade pública: um enfoque na contabilidade municipal. (2ª ed.) São Paulo: Atlas. 
Stiglitz, Joseph E. (1999). Economics of the Public Sector. (3a. ed.) New York: Norton \& Company.

Stock, J.H. \& Watson, M. W. (2004) Econometria: Tradução Monica Rosemberg. São Paulo: Addison Wesley.

Wooldridge, J. M. (2006). Introdução a Econometria: Uma abordagem moderna.Tradução R. C. Souza \& J. A. Ferreira, São Paulo: Pioneira Thomson Learning.

Yubero, F. D.; Lobo, M. L. D.; Verdugo, A. M. G.; Paramio, M. F.; Muñio, C. R.; Garcia, M. L.V.; Anel, J. L.; Conesca, F. M.; Ramos, J. J. M. \& Zuazu, M. G. R. (2009) La experiencia educativa de la Administración Tributaria Española. Instituto de Estudos Fiscales, 13/09. Madrid. Espanha.

Yubero, F.D.; Lobo, M. L. D. \& Garcia, M. L. V. (2008). Los impuestos, instrumentos de solidaridad El Programa de Educación Cívico-Tributaria de la Agencia Tributaria española. Instituto de Estudos Fiscales. Madrid. Espanha. 